\title{
Influence of Boundary Conditions on Cracking of Sanxingdui Moon Bay City Wall
}

\author{
Jin Qu, ${ }^{1}$ Jianlin $M a\left(\mathbb{D},{ }^{1}\right.$ and Bai Yang ${ }^{2,3}$ \\ ${ }^{1}$ School of Civil Engineering, Southwest Jiaotong University, Chengdu, Sichuan 610031, China \\ ${ }^{2}$ Faculty of Geosciences and Environmental Engineering, Southwest Jiaotong University, Chengdu 610031, China \\ ${ }^{3}$ School of Architecture and Transportation Engineering, Guilin University of Electronic Technology, Guilin 541004, China
}

Correspondence should be addressed to Jianlin Ma; majianlin01@126.com

Received 26 January 2020; Revised 22 May 2020; Accepted 13 July 2020; Published 28 July 2020

Academic Editor: Hayri Baytan Ozmen

Copyright $\odot 2020$ Jin Qu et al. This is an open access article distributed under the Creative Commons Attribution License, which permits unrestricted use, distribution, and reproduction in any medium, provided the original work is properly cited.

\begin{abstract}
The Sanxingdui Moon Bay City Wall, in China, is built of pale-yellow sand and yellow-brown clay, and the yellow-brown layers are suffering severely. In order to discuss the desiccation cracks in a section of this wall, this paper conducts evaporation tests in laboratory and observes the variations in the characteristics of the boundary conditions of the bottom surface of the sample. The results show that the boundary conditions of the bottom surface of the sample consist of two free boundaries, two sliding boundaries, and one fixed boundary from the outside to the inside. During the drying process, the free boundary extends, but the fixed boundary shrinks; the sliding boundary also remains basically stable. We obtain the surface tensile stress distribution under different boundary conditions through stress analysis and deduce that the tensile stress distribution has a trapezoidal pattern. Moreover, we calculate the lower limit on the crack spacing of the sample using the energy method, and the double of the sum of the maximum sliding boundary length and the free boundary length is the upper limit to the crack spacing. Maintaining the stability of the soil moisture content of the site is the main factor in the protection of the earthen archaeological site under the humid conditions of the museum above the site. In order to reduce the water evaporation rate of the soil, the surface of the site should be coated by a protectant, the main determining features of which are permeability, tensile strength, and compatibility with the earthen site.
\end{abstract}

\section{Introduction}

Masonry and earthen structures constitute a majority of the global historic buildings and are often referred to as unreinforced masonry and unfired Earth. These structures are highly vulnerable to damage such as rain erosion, cracking, undercutting, crumbling, and collapsing [1-3]. The cracking is the most common damage, which can be caused by desiccation, lack of drainage, earthquake, and structural deformation and is found in various types of historical structure spreading in both arid and humid regions [4-7].

The prevention and the treatment of shrinkage cracks in earthen ruins in the humid areas have been of interest during cultural relic protection since the mechanism of shrinkage cracking is complex, the influencing factors are numerous, and there are conflicts with the control measures of other types of damage. For example, building a museum on an earthen ruin can effectively prevent the damage from the wind and rain erosion, but it produces a dry environment for the earthen ruin and promotes the evaporation of water in the soil, which leads to large-scale cracking of the soil. Strengthening measures by infiltration and coating a protective layer on the surface of the earthen ruin can efficaciously improve the strength and continuity of the soil, while they themselves may cause more cracking [8].

In the process of water evaporation and soil shrinkage, the soil is subject to boundary restraint and generates tensile stress internally. Next, cracks are formed when the generated tensile stress exceeds the tensile strength of the soil [9]. On the other hand, when the ratio of the soil layer thickness to the friction of the contact surface is large, the contact surface is prone to slip [10]. Moreover, the tensile stress distribution 
on the soil surface has a triangular pattern, and the maximum tensile stress is located in the middle of the soil layer [11]. According to the strength criterion, an expression for the crack spacing can be obtained [12]. However, when the ratio of the soil layer thickness to the frictional force of the contact surface is small, the contact surface is suppressed, and the equation proposed by Price [12] is unable to predict the crack spacing [13]. Therefore, it is necessary to consider the variation of the shear stress along the thickness. Cox [14] used a two-dimensional model to analyze the tensile stress distribution when the soil-substrate contact surface is fixed. Through the numerical analysis, Peron et al. [15] found that the tensile stress on the top surface of the soil layer is evenly distributed and then calculated crack spacing according to the energy balance method. Ji chao et al. [16] proposed a crack spacing formula under fixed boundary conditions by analyzing the stress state of unsaturated soils and using the tensile strength criterion. Costa et al. [17] employed the tensile strength criterion and the energy balance method to analyze the crack spacing, and the energy balance method attained the minimum crack spacing.

Many investigators have researched the factors influencing cracking through lab-scale experimental examination, theoretical analysis, and numerical simulation. A higher temperature, a lower soil density, a greater soil thickness, and a higher friction of the contact surface will all cause a larger average crack area $[18,19]$. The ratio of the crack spacing to the thickness decreases by an increase in the soil thickness and variations in the mechanical properties of the soil [20]. However, the studies on cracking mechanism are based on a single boundary condition, and the influence of the variations in the boundary conditions on the crack spacing is not considered. Therefore, it is necessary to investigate the impact of the variations in the boundary conditions on the crack spacing.

In this work, a section of the Sanxingdui Moon Bay City Wall is discussed. A drying experiment is conducted, and the image of the displacement field of the cracking process is acquired by image processing and digital image correlation technology. By analyzing the shrinkage process of the sample, the variations in the characteristics of boundary conditions are obtained. Furthermore, the stress distribution under different boundary conditions is derived by stress analysis, and the variation of the crack spacing is further analyzed.

\section{The Sanxingdui Moon Bay City Wall}

The Sanxingdui site, whose history dates from 4000 years ago, is located in Guanghan City, Sichuan Province, China, as shown in Figure 1 and belongs to the warm and humid subtropical Pacific monsoon climate zone. The total length of the Moon Bay City Wall is about $650 \mathrm{~m}$, and its top width, bottom width, and height are, respectively, 20, 43 , and $2.8 \mathrm{~m}$; the section geometry of the wall is depicted in Figure 2(a). The wall is constructed at various sloping soil levels from A to $\mathrm{B}$, and slopes $\mathrm{G}$ and $\mathrm{H}$ are the banks of the wall. Each slope is compacted by a number of layers as can been seen in Figure 2(b), and two kinds of material, namely, pale-yellow

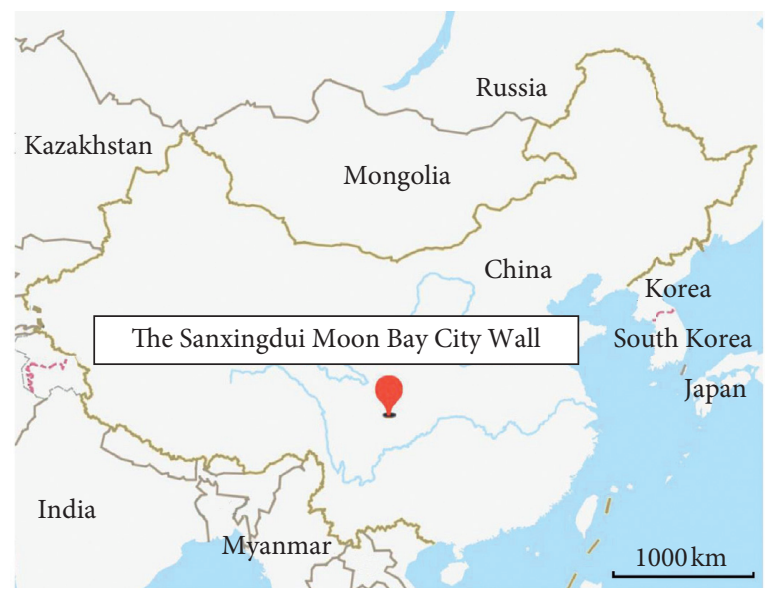

Figure 1: The location map of the Sanxingdui Moon Bay City Wall.

sand and yellow-brown clay, are used in the wall. The yellowbrown layers are mostly long strips sandwiched in the middle of the pale-yellow layers and randomly distributed with a height ranging from 1.2 to $2.6 \mathrm{~m}$ and a thickness between 58 and $325 \mathrm{~mm}$. Due to the lack of protection, parallel cracks are concentrated on the yellow-brown layer and distributed vertically. The shrinkage cracks destroy the continuity of the surface of the earthen ruins, which causes the surface soil to peel off, leads to local collapse, and exposes the internal fresh soil to continuous deterioration [21].

Cracking and spalling are the major defect on the yellowbrown layers. The ratio of the total area of cracking and spalling to the area of the layer is defined as the damage ratio. The damage ratio of each yellow-brown layer in slope $\mathrm{D}$ was obtained by using Adobe Photoshop software to extract cracking and spalling area. The water content of the yellowbrown layers in slope D was recorded by $\mathrm{ECH} 2 \mathrm{O}$ water content monitoring system, which has a precision of $2 \%$; the length of $\mathrm{ECH} 2 \mathrm{O}$ probe is $0.1 \mathrm{~m}$. The monitoring time was from May 26, 2017, to August 25, 2017.

Figure 3 delineates the variations of damage ratio and water content as a function of the central height of the yellow-brown layers in slope D. As the central height increases, the water content decreases, while the damage ratio increases. Cracking and spalling of soil are related to mineral composition, particle structure, particle gradation, density, moisture content, salt content, boundary conditions, specimen size, initial stress, stress path, drying-wetting cycle, and so on [18, 22-27]. According to Figure 3, the damage ratio of the layers has a strong correlation with water content. The lower the water content, the greater the damage ratio.

\section{Materials and Methods}

3.1. Test Materials. The soil specimens were obtained from a section of the yellow-brown portion of the Moon Bay City Wall. The properties and mineral composition of the soil are tabulated in Tables 1 and 2, respectively. Filter paper method was used to measure the matric suction of soil with a water content varying from 35 to $66 \%$. The soil-water characteristic curve (SWCC) is then obtained as shown in Figure 4. 


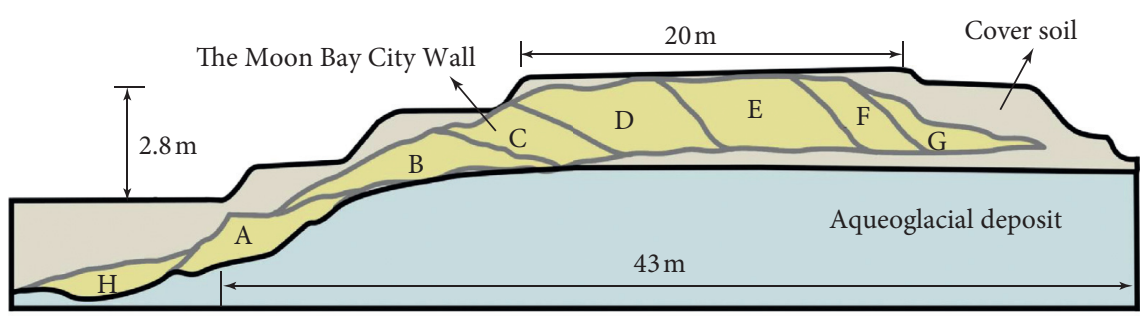

(a)

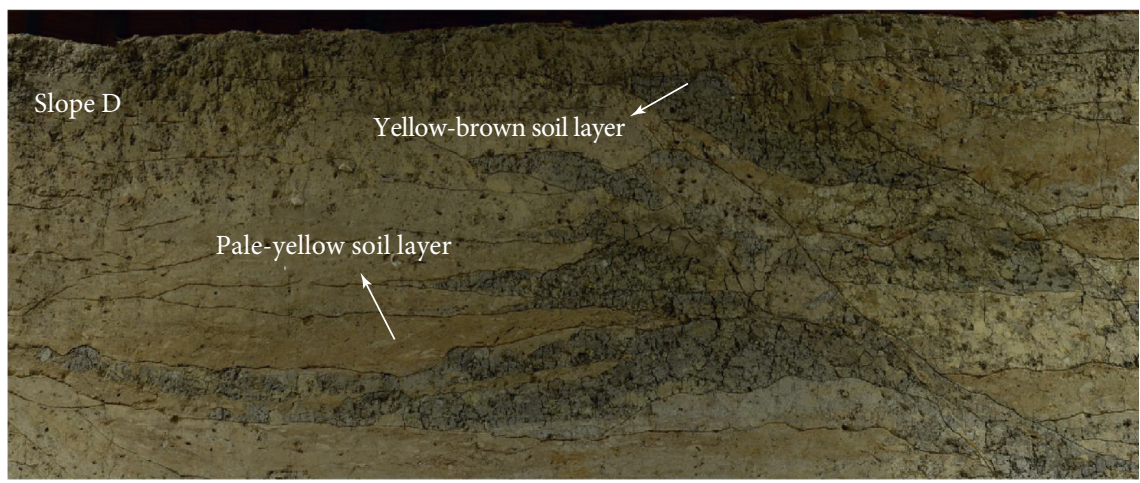

(b)

Figure 2: The profile of the Moon Bay City Wall. (a) A section of Moon Bay City Wall. (b) Slope D of the above section.

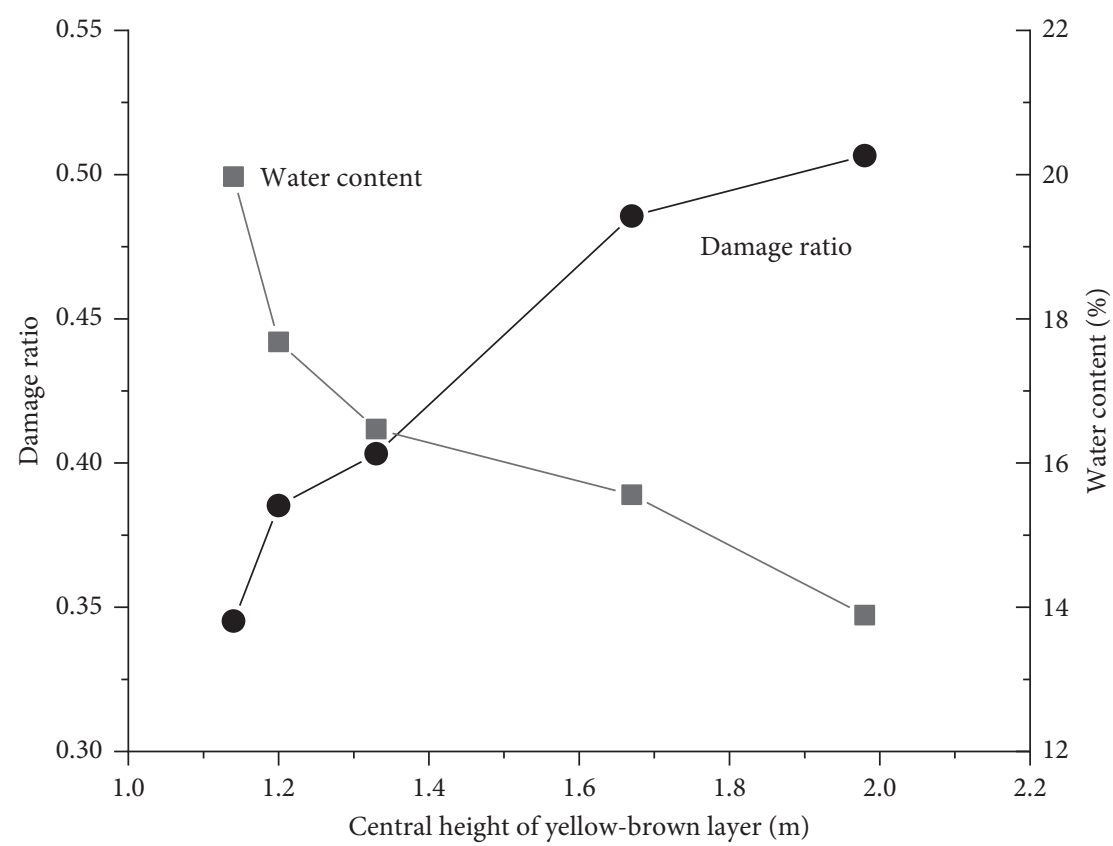

Figure 3: The variations of damage ratio and water content as a function of the central height of the yellow-brown layers in slope D.

3.2. Test Setup. The plexiglass mold used has a length, width, and height of 600,40 , and $50 \mathrm{~mm}$, respectively. In order to observe the shrinkage process from the side view, the four side panes of the plexiglass setup are removable. To increase the friction of the bottom surface of the layer, 100-mesh sandpaper is glued to the glass matrix. During the drying process, moisture evaporates from the top and lateral surfaces of the soil layer.
The test box of the setup (see Figure 5) has a length of $700 \mathrm{~mm}$, a width of $400 \mathrm{~mm}$, and a depth of $600 \mathrm{~mm}$. One hole is punched on the bottom of the test box, and a dryer is installed outside of the test box. Then, one end of the air duct is connected to the dryer outlet, and the other end is inserted through the hole, which is placed along the central axis on the bottom of the test box to prevent hot air from directly blowing on the sample, thereby resulting in uneven heating 
Table 1: Properties of the soil.

\begin{tabular}{lc}
\hline Property & Value \\
\hline Liquid limit (\%) & 45.4 \\
Plastic limit (\%) & 24.6 \\
Plasticity index (\%) & 20.8 \\
Free swelling ratio (\%) & 63.5 \\
Specific gravity & 2.70 \\
Angle of internal friction $\left(^{\circ}\right)$ & 19 \\
Cohesion $(\mathrm{kPa})$ & 24 \\
\hline
\end{tabular}

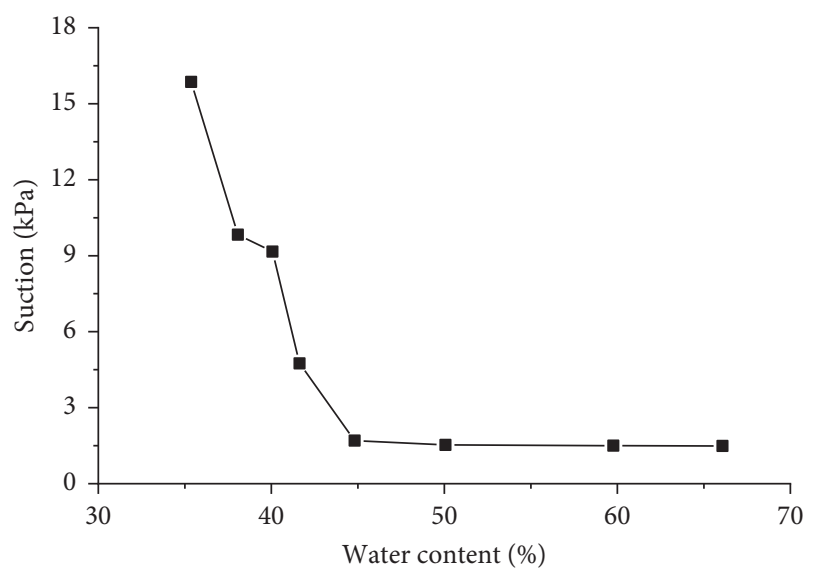

FIGURE 4: Relationship between matric suction and water content.

of the soil. The sample is placed on two electronic scales connected to a personal computer. The imaging system consists of two photographic lights and a normal-focal-length macro lens $(50 \mathrm{~mm})$ on a $35 \mathrm{~mm}$ digital camera. The digital camera is fixed at a distance of $1.1 \mathrm{~m}$ from the sample, and the lens is parallel to the side of the sample. We adjust the position of the lamp holder to fully illuminate the specimen.

3.3. Test Procedure. The sample was sieved through a $0.5 \mathrm{~mm}$ sieve and stirred with distilled water to prepare a slurry with a water content of $55 \%$. Then, the mud was poured into the mold, and its surface was smoothed. Next, the sample was placed on a shaking table to remove air bubbles. Once the sample slightly dried, the four sides of the plexiglass mold were removed. Afterward, we turned on the dryer to preheat and increase the temperature of the test chamber. When the temperature of the test chamber is in the range of 26 to $30^{\circ} \mathrm{C}$, the prepared sample is placed on the scale. To calculate the water content of the sample, the data provided by the electronic scales were transferred every one minute. We also adjusted the camera and captured an image per minute to record the shrinkage process. During the test, when the weight of the sample changed less than one gram during two hours of heating, the drying process was considered to be complete. Each drying process was repeated three times.

\section{Results and Discussion}

4.1. Test Results. The vertical displacement field during the cracking process was herein obtained using VIC-2D software, as displayed in Figure 6. The sample settled at the
TABLE 2: Mineral composition of the soil.

\begin{tabular}{lc}
\hline Mineral & Percentage \\
\hline Quartz & 66.56 \\
Feldspar & 16.75 \\
Mica & 8.42 \\
Illite & 8.27 \\
\hline
\end{tabular}

beginning of the drying process, and the two ends of the specimen tended to tilt upwards. According to the displacement distribution, the settlement was gradually reduced from the top to the bottom surface and from the middle to the two ends. When the cracks were formed, the soil was separated from the bottom surface of the mold at both ends and was rapidly contracted inwards and upwards. As the drying progressed, the height and the area of the upturned portion of the sample gradually increased. At the end of the drying process, both ends of the sample began to fall back, and the middle was lifted upwards. The distribution of the vertical displacement field was arch-shaped with the upturned portion in the middle of the sample and two fallen ends.

Figure 7 displays the local displacement vector of the sample dried for $1150 \mathrm{~min}$. The sample is divided into three regions by using zero-displacement lines in the horizontal and vertical directions. In zone I, the horizontal displacement was nonzero, and the vertical displacement was greater than zero. Therefore, the soil was warped upwards, and the bottom surface was separated from the base to form a free boundary.

In zone II, the horizontal displacement was nonzero, and the vertical displacement was less than or equal to zero; in fact, the soil settled and contracted, and the bottom surface of the soil was in contact with the base; as a result, a relative movement formed a sliding boundary.

In zone III, the horizontal displacement was zero, and the vertical displacement was less than or equal to zero; indeed, the soil only settled vertically and was bonded to the base, and there was no relative movement; consequently, a fixed boundary was formed. Therefore, in the drying process, the bottom surface of the sample consisted of two free boundaries at the two ends, two sliding boundaries adjacent to the free boundaries, and a fixed boundary in the middle.

In order to investigate the development of the three types of boundary during the drying process, the variations in the length of the three types of boundary on the bottom surface of the sample were studied. It should be noted that the ratio of the length of the boundaries to the total length of the specimen varied with time. Hence, Figure 8 delineates the variation of the boundary conditions (in terms of the ratio of the length of the boundaries to the total length of the specimen) for a period of $2500 \mathrm{~min}$ as the boundary conditions changed due to the arched shape of the sample.

Before the cracks were formed, the sample was contracted towards the center as the drying process progressed; thus, the length ratio of the fixed boundary decreased, but the length ratio of the sliding boundary 

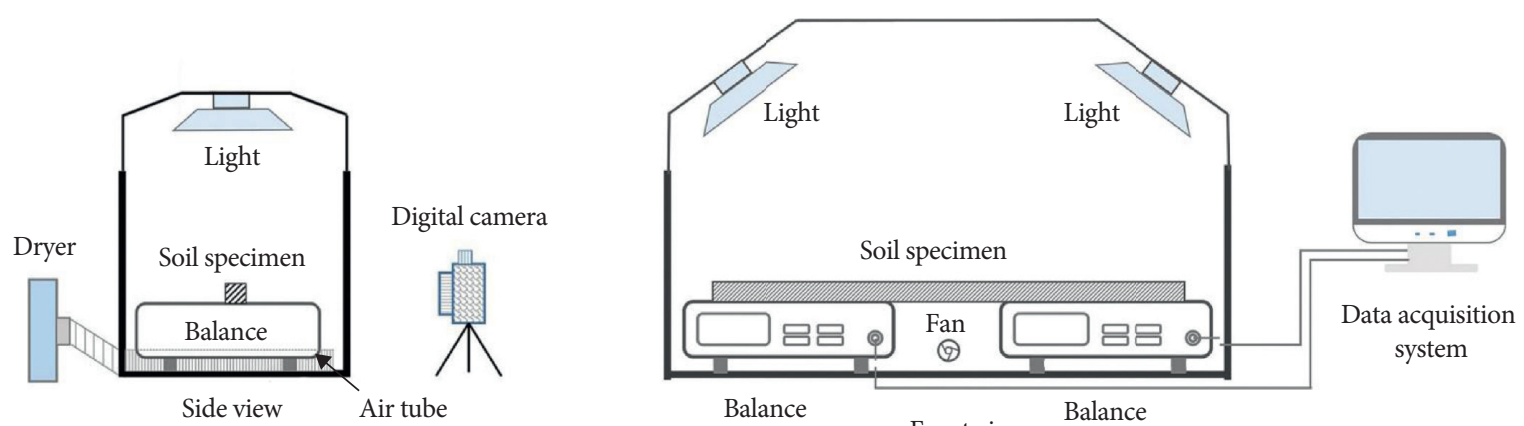

Figure 5: Test setup.

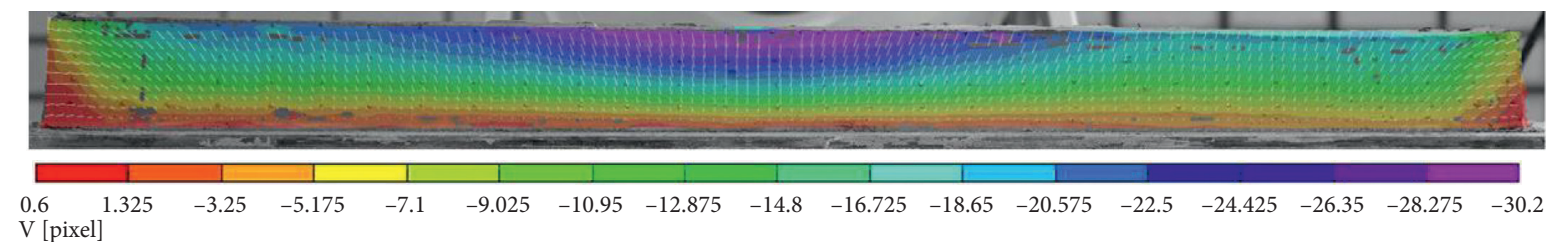

(a)

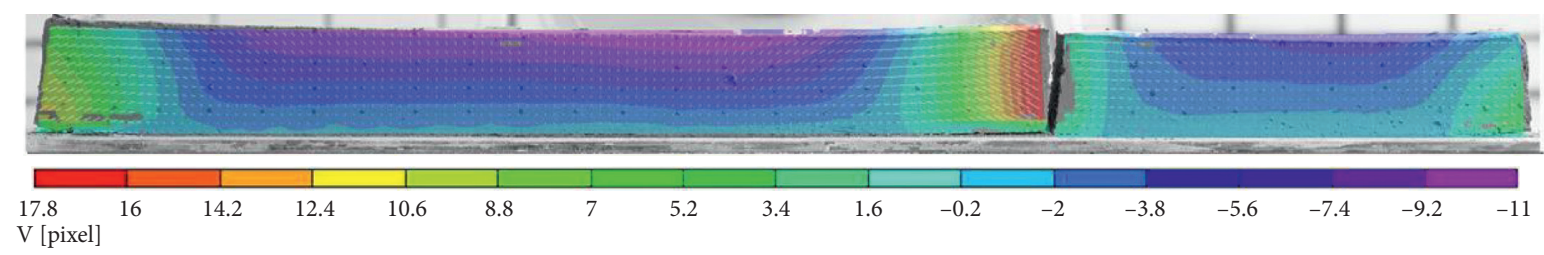

(b)

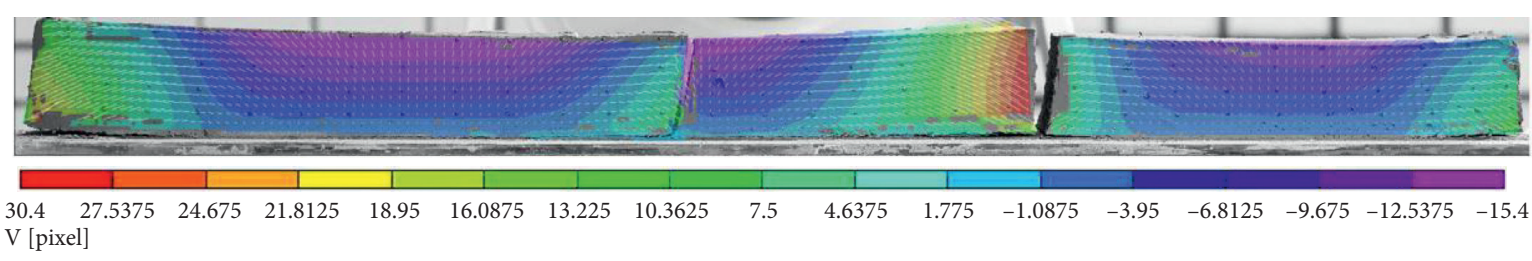

(c)

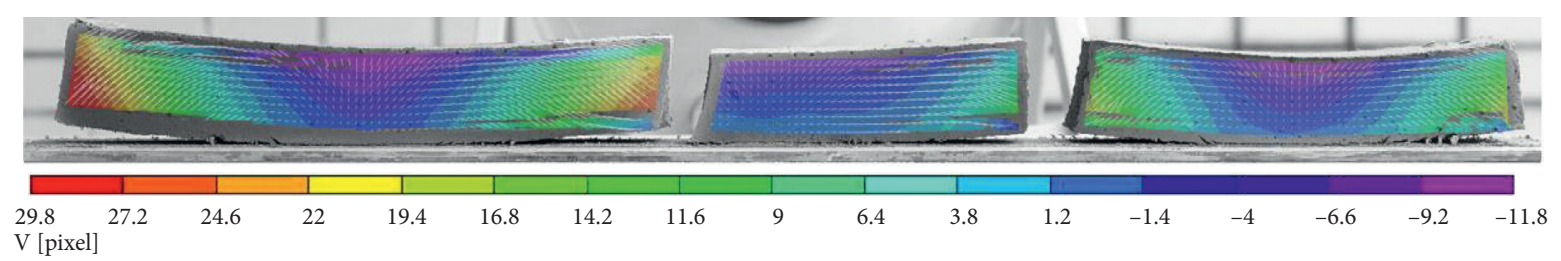

(d)

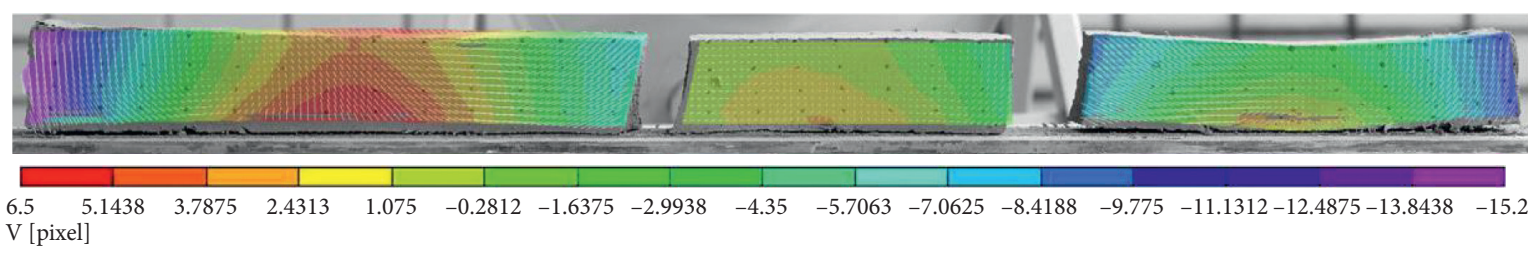

(e)

Figure 6: The vertical displacement fields over a drying period of (a) $850 \mathrm{~min}$; (b) $1050 \mathrm{~min}$; (c) $1200 \mathrm{~min}$; (d) $2000 \mathrm{~min}$; (e) $2500 \mathrm{~min}$.

gradually increased; the length ratio of the free boundary was almost equal to zero. When the cracks were formed at a time of $1230 \mathrm{~min}$, the length ratio of the fixed boundary plummeted, while that of the free boundary soared. The length ratio of the sliding boundary was almost stable with a slight variation. 


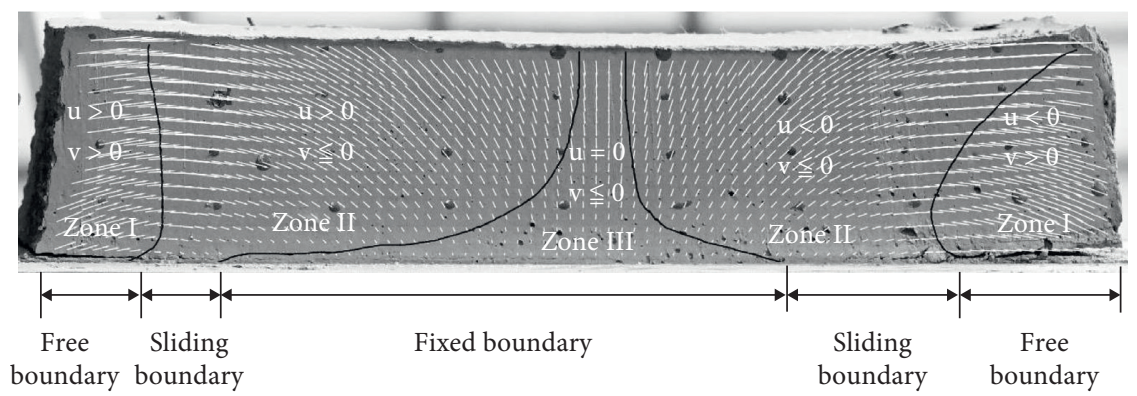

FIgURE 7: The displacement field of the right block after drying for $1150 \mathrm{~min}$.

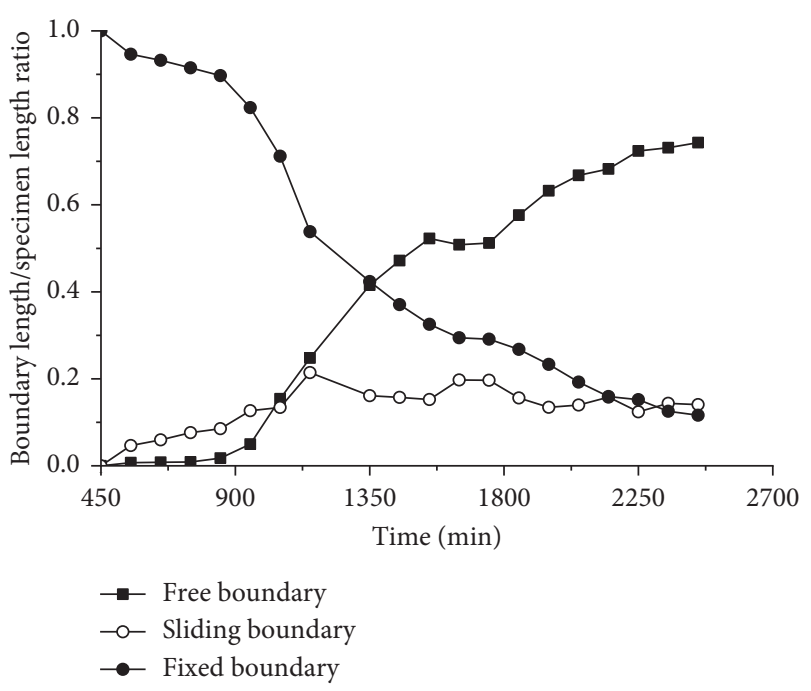

FIgURE 8: The variations in the ratio of the length of the boundaries to the total length of the specimen as a function of time.

\section{Discussion}

During the drying process, different boundary conditions are formed between the bottom surface of the soil layer and the base. The distribution and the variation of boundary conditions affect the cracking pattern and the crack spacing. Therefore, in this section, we discuss the stress distribution characteristics under different boundary conditions, develop a stress distribution model during the drying process, analyze the soil layer cracking pattern, and further predict the crack spacing.

It is assumed that the length of the soil layer is $2 L$, and its thickness is $d$. The soil layer is supposed to be an isotropic, homogeneous, and elastic material. The cracks are usually formed through the soil layer in the thickness direction. Provided the evaporation rate is identical in the horizontal direction and the water content does not change much in the horizontal direction compared to the vertical direction for the same soil layer, the stress analysis can be simplified to a plane strain problem since the water content is also uniform in the horizontal direction. Since the cracking time is short relative to the entire drying process, it is assumed that the material properties remain intact during the cracking process. Considering the symmetry of the soil layer and the stress on the soil layer, only a half symmetry plane is analyzed. The stresses acting on the element in the horizontal direction are depicted in Figure 9. The evaporation of moisture causes the soil to shrink towards the inside, thus a horizontal stress is generated between the bottom surface of the soil and the base. The shear stress on the element is represented by $\tau$, and $\sigma_{x}$ stands for the horizontal tensile stress.

When the bottom surface of the soil layer is fixed, its displacement is zero. The stress balance condition in the horizontal direction is therefore expressed by

$$
\sigma_{x} \mathrm{~d} z-\left(\sigma_{x}+\mathrm{d} \sigma_{x}\right) \mathrm{d} z+\tau \mathrm{d} x-(\tau+\mathrm{d} \tau) \mathrm{d} x=0 .
$$

Equation (1) can then be rearranged as follows:

$$
\frac{\partial \sigma_{x}}{\partial x}=-\frac{\partial \tau}{\partial z}
$$

The change of normal stress in $y$-direction is ignored, and the element is assumed to be in the plane strain. According to the elastic theory, $\sigma_{x}$ can be written as

$$
\sigma_{x}=-\frac{E}{\left(1-v^{2}\right)} \frac{\partial u}{\partial x},
$$

where $E$ is Young's modulus and $v$ represents Poisson's ratio; $u$ stands for the correspondent horizontal displacement. Neglecting the vertical displacement caused by the shear strain component, $\tau$ can be given by

$$
\tau=-G \frac{\partial u}{\partial z}
$$

where $G$ is the shear modulus. Based on the results of the laboratory test, the horizontal displacement of the fixed boundary condition is described by (5). The analysis is discussed in detail elsewhere [28]:

$$
u=u_{0}\left(1-\frac{z^{2}}{d^{2}}\right),
$$

where $u_{0}$ is the horizontal displacement at the top of the soil sample.

By substituting (5) into (4), we obtain $\tau$ as given in

$$
\tau=\frac{2 G}{d^{2}} u_{0} z
$$

The boundary conditions are as follows: $\tau=0$ when $z=$ 0 and $u=0$.

Substituting (6) into (2) returns 


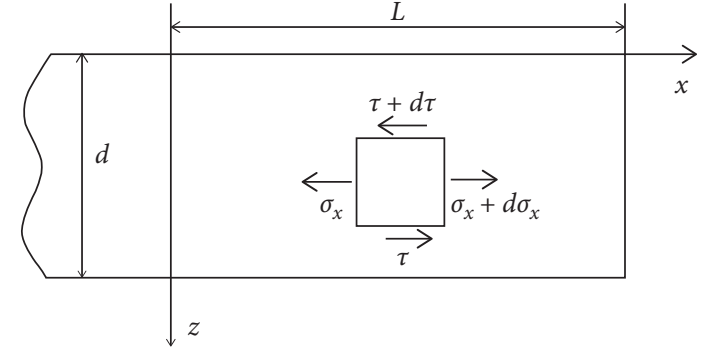

Figure 9: A schematic of the stresses on the element in the horizontal direction.

$$
\frac{\partial \sigma_{x}}{\partial x}=-\frac{2 G}{d^{2}} u_{0}
$$

When tensile stress $\sigma_{x 0}$ is considered, (3) is rewritten as (8), which is established for the top of the soil specimen:

$$
\frac{\partial u_{0}}{\partial x}=-\frac{\sigma_{x 0}\left(1-v^{2}\right)}{E} .
$$

Using (7) and (8), we derive

$$
\frac{\partial^{2} \sigma_{x 0}}{\partial x^{2}}=\frac{(1-v)}{d^{2}} \sigma_{x 0}
$$

Integrating (9) twice with respect to $x$ yields

$$
\ln \left[\frac{\sigma_{x 0}}{C_{1}}+\sqrt{\left(\frac{\sigma_{x 0}}{C_{1}}\right)^{2}+1}\right]= \pm \sqrt{1-v} \frac{x}{d}+C_{2}
$$

where $C_{1}$ and $C_{2}$ are integration constants. When $\sqrt{1-v}=\lambda$, (10) can be rewritten as follows:

$$
\operatorname{arsh}\left(\frac{\sigma_{x 0}}{C_{1}}\right)= \pm \lambda \frac{x}{d}+C_{2} \text {. }
$$

Solving (11) based on the following boundary conditions yields (12).

When $x=0, \sigma_{x 0}=\sigma_{0}$ and when $x=L, \sigma_{x 0}=0$;

$$
\sigma_{x 0}=\sigma_{0}\left[\operatorname{ch}\left(\lambda \frac{x}{d}\right)-\operatorname{cth}\left(\lambda \frac{L}{d}\right) \operatorname{sh}\left(\lambda \frac{x}{d}\right)\right] .
$$

Also, when the boundary condition on the bottom surface of the soil layer is a sliding boundary, there is a relative displacement. According to (5), the lateral horizontal displacement of the soil layer can be expressed by

$$
u=u_{0}-\left(u_{0}-u_{d}\right) \frac{z^{2}}{d^{2}}
$$

where $u_{d}$ is the horizontal displacement at the bottom of the soil layer. Substituting (13) into (4) returns (14), from which (15) can be derived:

$$
\begin{aligned}
& \tau=\frac{2 G}{d^{2}}\left(u_{0}-u_{d}\right) z, \\
& \tau=-\frac{\tau_{d}}{d} z,
\end{aligned}
$$

where $\tau_{d}$ is the shear stress at the bottom of the soil layer. By using (15) and (2) and applying the boundary condition of $\sigma_{x 0}=0$ when $x=L$, we derive

$$
\sigma_{x 0}=\frac{\tau_{d}}{d}(L-x) .
$$

When the bottom surface of the soil layer is free, that is, we have a free boundary, the soil layer can be freely contracted, and the tensile stress is zero.

The length of the fixed boundary, sliding boundary, and free boundary is represented by $L_{1}, L_{2}$, and $L_{3}$, respectively. According to the test results, the bottom surface of the soil layer is transformed from the fixed boundary to the sliding boundary and then to the free boundary during the drying process. Therefore, the tensile stress on the top surface of the soil layer can be expressed as follows:

$$
\left\{\begin{array}{l}
\sigma_{x 0}=\sigma_{0}\left[\operatorname{ch}\left(\lambda \frac{x}{d}\right)-\operatorname{cth}\left(\lambda \frac{L}{d}\right) \operatorname{sh}\left(\lambda \frac{x}{d}\right)\right], \quad 0 \leq x \leq L_{1}, \\
\sigma_{x 0}=\sigma_{1}-\frac{\tau_{d}}{d}\left(x-L_{1}\right), \quad L_{1}<x \leq L_{1}+L_{2}, \\
\sigma_{x 0}=0, \quad L_{1}+L_{2}<x \leq L,
\end{array}\right.
$$

where $\sigma_{1}$ is the tensile stress at the top of the specimen when $x=L_{1}$.

The length of the sliding boundary at a given moisture content can be obtained according to

$$
L_{2}=\frac{\sigma_{1} d}{\tau_{d}} .
$$

The water evaporation rate is greater on the surface of the soil layer, which results in a nonuniform stress distribution and consequently causes bending moments [29]. Thus, the soil at both ends of the soil layer and on the two sides of the crack is lifted up to form a free boundary. Under free boundary conditions, the shrinkage is free, and the vertical bending moment of the soil layer is zero. Therefore, the bending moment at the boundary between the free boundary and the sliding boundary can be expressed by

$$
M=\int_{0}^{d} \sigma_{c}\left(\frac{1}{2} d-z\right) d z-\frac{1}{2} \sigma_{z}(L-x)^{2}=0,
$$

where $\sigma_{c}$ is the horizontal compressive stress and $\sigma_{z}=\gamma d(1+\omega)$ represents the vertical normal stress at the bottom; $\gamma$ is the unit weight of the soil, and $\omega$ stands for the water content. It is also assumed that the internal compressive stress of the soil layer is linearly distributed along the thickness direction, and the length of the free boundary is expressed by

$$
L_{3}=\sqrt{\frac{d^{2} \Delta \sigma}{6 \sigma_{z}}}
$$


where $\Delta \sigma$ represents the stress difference between the top and the bottom of the soil layer. In the initial state, $\Delta \sigma=0$ and the water evaporation begins from the top surface of the soil layer; then, it happens in the soil layer, which leads to the gradual increase of $\Delta \sigma$. As the evaporation progresses, the water content in the soil layer tends to be uniform, and $\Delta \sigma$ slowly decreases to zero. Since $\Delta \sigma$ rises first but then drops to zero during the evaporation and $\sigma_{2}$ decreases all the time, the free boundary first grows but then shrinks. The two ends of the soil layer are first upturned but then fall back gradually, which is consistent with the phenomenon observed in the experiment.

According to the tensile strength criterion, when the maximum tensile stress reaches the limit, a crack is formed. It can be inferred from (17) that the entire fixed boundary fulfills the cracking condition; thus, cracks can be formed at any position within the range of $L_{1}$, and they can be produced in a single piece or in multiple pieces at the same time [15]. The location of the cracks is related to the distribution of internal defects and the local water evaporation rate [9].

When $\tau_{d}>\tau_{f}$, where $\tau_{f}$ is the shear stress of the soil, the fixed boundary is transformed into the sliding boundary. $\tau_{d}$ could also be expressed by

$$
\tau_{d}=\sigma_{z} \tan \varphi,
$$

where $\varphi$ is the internal friction angle. If we set $\sigma_{1}=\sigma_{f}$ in (18), the maximum length of the sliding boundary for a given water content can be calculated as $L_{2 \max }$.

According to the law of conservation of energy, the elastic strain energy is released due to crack formation and converted into surface energy [30]. It is assumed that the energy is completely released, and the minimum crack spacing $(s)$, defined by (22), is obtained [18]:

$$
s=\frac{2 E G_{c}}{\sigma_{f}^{2}},
$$

where $N$ is the number of cracks and $G_{c}$ stands for the critical release rate of strain.

The cracks divide the layer into small parts, thereby creating new fracture surfaces. The tensile stress is gradually developed during the drying process until another crack is formed again. During the cracking process, when $L$ is reduced, $L_{1}$ is decreased, but $L_{2}$ and $L_{3}$ are increased. When $L<\left(E G_{c}\right) / \sigma f^{2}$, only monotonous cracks are formed in the middle area of the soil layer. However, when $L_{1}=0$ and $L<L_{2 \max }+L_{3}$, no more cracks are formed. Therefore, we assume that there is no defect in the soil, and the maximum crack spacing is not greater than twice as large as the sum of the lengths of the sliding boundary and the free boundary. The theoretical range of the crack spacing is expressed by

$$
\frac{2 E G_{c}}{\sigma_{f}^{2}} \leq s \leq 2\left[\frac{\sigma_{f} d}{\tau_{d}}+\sqrt{\frac{d^{2} \Delta \sigma}{6 \sigma_{z}}}\right] .
$$

To verify (23), a dry test was performed and repeated four times, on a sample with a length, width, and height of 600,40 , and $15 \mathrm{~mm}$, respectively. The sample preparation was done as described in Section 2.4. All the cracks were formed in the samples between the state of liquid limit and the state of plastic limit. The crack spacing was measured and counted after the crack was stabilized. The final crack patterns and the statistical results are illustrated in Figures 10 and 11, respectively. The crack spacing ranges from 2.24 to $13.30 \mathrm{~cm}$.

Based on the observations of the experimental data and empirical estimations [31-33], we set $G_{c}$ at $1 \mathrm{~N} / \mathrm{m}$. The lower limit on the crack spacing calculated by $(22)$ is $0.11 \mathrm{~cm} . \tau_{d}$ can also be calculated by (21). According to the theory of unsaturated soil mechanics, the tensile strength of unsaturated soil can be calculated by the following equation [26]:

$$
\sigma_{t}=c_{\text {app }} \cos \varphi(1+\sin \varphi),
$$

where $c_{\text {app }}=c+c_{c} ; c_{\text {app }}$ and $c_{c}$ stand for the apparent cohesion and the microcohesion, respectively. The maximum length of the sliding boundary calculated by (18) is $1.7 \mathrm{~cm}$, and the length of the free boundary figured by (20) is $7.8 \mathrm{~cm}$. According to (23), the crack spacing ranges from 0.11 to $19 \mathrm{~cm}$. Generally, the calculated values conform to the measured results.

Based on the above analyses, the key factor in the protection of earthen ruins in the museum located in a wet area is to maintain the level of the water content of the soil to prevent shrinkage which may cause cracking. Firstly, the groundwater level and the temperature and humidity of the museum above the earthen ruins should be stabilized so that the sites remain in a relatively stable environment. Secondly, the surface of the earthen ruins should be coated with a protectant to suppress the loss of water. Since surface protection materials used in the earthen ruins are exposed to the open air, the water repellency and the water stability of the material and the compressive strength of the soil coated with the protectant are the main concerns for evaluating protectants. Meanwhile, in order to decrease the number of cracks in the earthen ruins, the water evaporation rate of the soil should be reduced, while the tensile strength of the soil should be increased. Therefore, when selecting a protectant, the permeability and the tensile strength of the coated soil should be considered. Additionally, the protectant needs to have deformation characteristics similar to the soil. Furthermore, during the coating, the protectant should have a certain penetration depth, and the concentration gradient of the protectant should be controlled to avoid the formation of a new interface in the soil, which may result in a greater shear stress and more cracks. For the site with cracks, grouting reinforcement is needed to increase the continuity of the surface and to prevent water loss. The strength of the grouting material should be slightly lower than the strength of the soil, which will reduce the constraining effect of the boundary and prevent the soil from cracking due to the shrinkage process. 

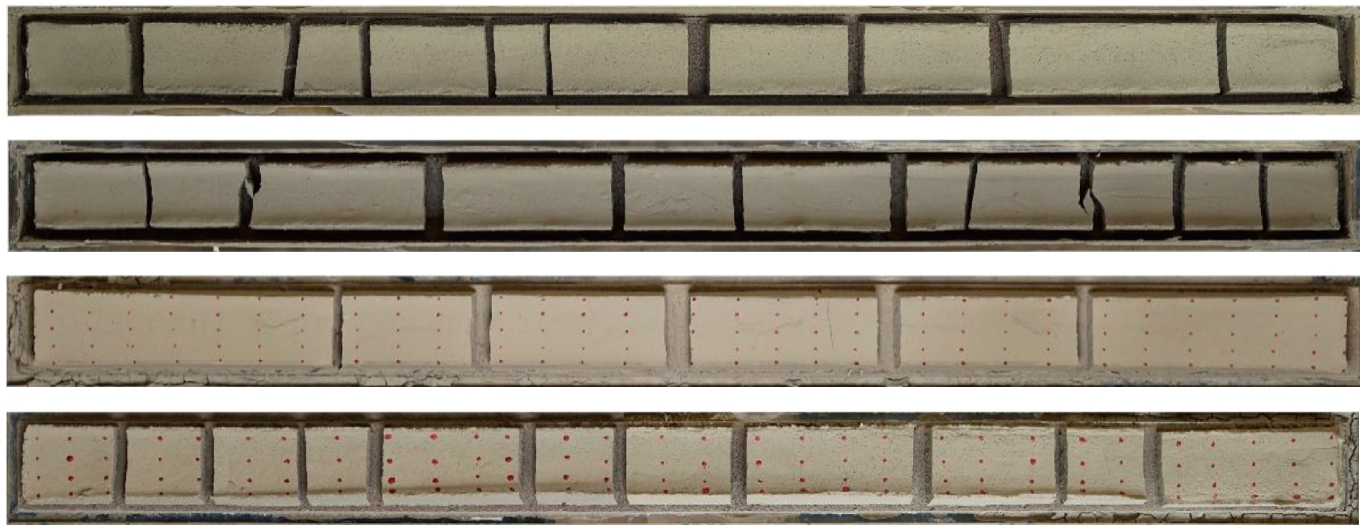

FIgURE 10: The final crack patterns.

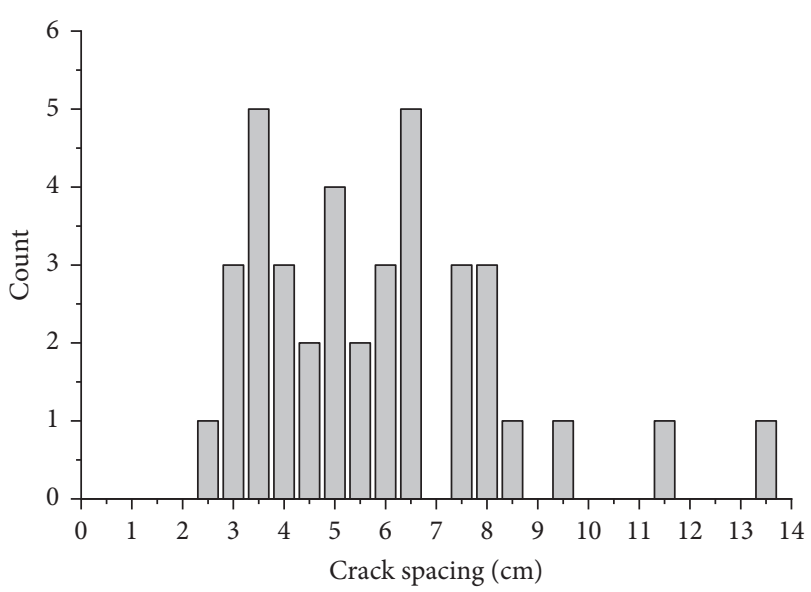

FIGURE 11: Distribution of the crack spacing.

\section{Conclusions}

The results of an experimental study on desiccation cracks were presented, and the variations in the characteristics of the boundary conditions of the bottom surface of the soil layer were studied. The tensile stress distribution was deduced, and the crack spacing was discussed. Based on these analyses, the following conclusions can be drawn:

(i) During the drying process, the bottom surface of the soil layer consists of two free boundaries, two sliding boundaries, and a fixed boundary. The free boundary grows, but the fixed boundary shrinks greatly; the sliding boundary remains basically unchanged.

(ii) When the bottom surface of the soil layer is fixed, the tensile stress distribution on the top surface of the soil layer is an inverse trigonometric function; however, when the bottom surface of the soil layer slips, the tensile stress on the top surface of the soil layer is a linear function. During the cracking process, the tensile stress distribution on the surface of the soil layer has a trapezoidal shape.

(iii) The energy balance method can obtain the lower limit on the crack spacing, and the double of the sum of the maximum sliding boundary length and the free boundary length is the upper limit to the crack spacing.

(iv) The crucial factor in the protection of earthen ruins in wet areas is to stabilize the level of the water content of the site and to control the groundwater level and the temperature and humidity of the museum above the site. The surface of the site should be coated with a protectant, and the cracks should be filled with grout. At the same time, attention should be paid to the permeability and the tensile strength of the protectant and the grouting material and to the compatibility of the protectant to reduce the constraints on the soil layer and avoid further cracking of the soil.

\section{Data Availability}

The data used to support the findings of this study are available from the corresponding author upon request.

\section{Conflicts of Interest}

The authors declare that there are no conflicts of interest regarding the publication of this manuscript.

\section{References}

[1] M. Puppio and L. Giresini, "Estimation of tensile mechanical parameters of existing masonry through the analysis of the collapse of Volterra's urban walls," Frattura Ed Integrità Strutturale, vol. 13, no. 49, pp. 725-738, 2019.

[2] M. Andreini, A. De Falco, L. Giresini, and M. Sassu, "Collapse of the historic city walls of pistoia (Italy): causes and possible interventions," Applied Mechanics and Materials, vol. 352, pp. 1389-1392, 2013.

[3] M. Sassu, L. Giresini, and M. L. Puppio, "Failure scenarios of small bridges in case of extreme rainstorms," Sustainable and Resilient Infrastructure, vol. 2, pp. 1-9, 2017.

[4] M. L. Sun, "The present condition of protection and development in earthen sites," Sciences of Conservation and Archaeology, vol. 19, no. 4, pp. 64-70, 2007.

[5] H. Y. Zhang, M. Li, and X. D. Wang, "Status and countermeasures of conservation of earthen monuments in moist circumstances," Dunhuang Research, vol. 6, pp. 70-75, 2011. 
[6] Z. Q. Guo, W. W. Chen, and K. W. Zhang, "Dependence of the fissures in the ancient rammed-earthen sites on the meteorological factors of the northwestern of China," Journal of Engineering Geology, vol. 24, no. 1, pp. 128-136, 2016.

[7] J. Y. Wang, "The investigation on the current condition of mogao grottoes and the classification of diseases in exist," Dunhuang Research, vol. 6, pp. 113-117, 2005.

[8] Y. Y. Xu, S. J. Wang, and B. J. Zhang, "Investigation and research on relics diseases of the earthen site of Kuahuqiao site museum," Sciences of Conservation and Archaeology, vol. 30, no. 1, pp. 53-62, 2018.

[9] H. Peron, T. Hueckel, L. Laloui, and L. B. Hu, "Fundamentals of desiccation cracking of fine-grained soils: experimental characterisation and mechanisms identification," Canadian Geotechnical Journal, vol. 46, no. 10, pp. 11771201, 2009.

[10] M. P. J. Schöpfer, A. Arslan, J. J. Walsh, and C. Childs, "Reconciliation of contrasting theories for fracture spacing in layered rocks," Journal of Structural Geology, vol. 33, no. 4, pp. 551-565, 2011.

[11] A. Kelly and W. R. Tyson, "Tensile properties of fibre-reinforced metals: copper/tungsten and copper/molybdenum," Journal of the Mechanics and Physics of Solids, vol. 13, no. 6, pp. 329-350, 1965.

[12] N. J. Price, "Brittle fracture," Fault and Joint Development in Brittle and Semi-brittle Rock, vol. 2, pp. 1-56, 1966.

[13] T. Bai, D. D. Pollard, and H. Gao, "Explanation for fracture spacing in layered materials," Nature, vol. 403, no. 6771, pp. 753-756, 2000.

[14] H. L. Cox, "The elasticity and strength of paper and other fibrous materials," British Journal of Applied Physics, vol. 3, no. 3, pp. 72-79, 2002.

[15] H. Peron, L. Laloui, L. Hu, and T. Hueckel, "Formation of drying crack patterns in soils: a deterministic approach," Acta Geotechnica, vol. 8, 2012.

[16] S. Ji chao, G. Wang, and Q. Sun, "Crack spacing of unsaturated soils in the critical state," Chinese Science Bulletin, vol. 54, pp. 2008-2012, 2009.

[17] S. Costa, J. Kodikara, S. Barbour, and D. Fredlund, "Theoretical analysis of desiccation crack spacing of a thin, long soil layer," Acta Geotechnica, vol. 13, pp. 39-49, 2017.

[18] S. Costa, J. Kodikara, and B. Shannon, "Salient factors controlling desiccation cracking of clay in laboratory experiments," Géotechnique, vol. 63, pp. 18-29, 2012.

[19] C. Tang, B. Shi, C. Liu, B. J. Wang, and W. Gao, "Developing law and morphological analysis of shrinkage cracks of clayey soil under different temperatures," Yantu Gongcheng Xuebao/ Chinese Journal of Geotechnical Engineering, vol. 29, pp. 743-749, 2007.

[20] H. Nahlawi and J. K. Kodikara, "Laboratory experiments on desiccation cracking of thin soil layers," Geotechnical and Geological Engineering, vol. 24, no. 6, pp. 1641-1664, 2006.

[21] K. B. Ren, B. Wang, and X. M. Li, "Strength properties and pore-size distribution of earthen archaeological site under dry-wet cycles of capillary water," Rock and Soil Mechanics, vol. 40, no. 3, pp. 962-970, 2019.

[22] L. Pauchard, C. F. Parisse, and C. Allain, "Influence of salt content on crack patterns formed through colloidal suspension desiccation," Physical Review E, vol. 59, no. 3, pp. 3737-3740, 1999.

[23] K. F. Decarlo and N. Shokri, "Salinity effects on cracking morphology and dynamics in 3-D desiccating clays," Water Resources Research, vol. 50, no. 4, pp. 3052-3072, 2014.
[24] B. A. Albrecht and C. H. Benson, "Effect of desiccation on compacted natural clays," Journal of Geotechnical and Geoenvironmental Engineering, vol. 127, no. 1, pp. 67-75, 2001.

[25] C. S. Tang, B. Shin, and C. Liu, "Influencing factors of geometrical structure of surface shrinkage cracks in clayey soils," Engineering Geology, vol. 101, no. 3-4, pp. 204-217, 2001.

[26] M. R. Lakshmikantha, P. C. Prat, and A. Ledesma, "Experimental evidence of size effect in soil cracking," Canadian Geotechnical Journal, vol. 49, no. 3, pp. 264-284, 2012.

[27] C. A. Tang, Y. B. Zhang, and Z. Z. Liang, "Fracture spacing in layered materials and pattern transition from parallel to polygonal fractures," Physical Review E, vol. 73, no. 5, p. 56120, 2006.

[28] J. Qu, J. L. Ma, and B. Yang, "Deterioration characteristic features of the crack on the section of Sanxingdui," Journal of Safety and Environment, vol. 20, no. 3, pp. 959-968, 2020.

[29] J. Kodikara, H. Nahlawi, and A. Bouazza, "Modelling of curling in desiccating clay," Canadian Geotechnical Journal, vol. 41, pp. 560-566, 2011.

[30] Z. P. Bažant and L. Cedolin, "Stability of structures: elastic, inelastic, fracture and damage theories," 2010.

[31] V. Thakur and D. Niggusie, "Run-out of sensitive clay debris: significance of the flow behavior of sensitive clays," Geotechnical Engineering, vol. 45, pp. 80-90, 2014.

[32] M. R. Lakshmikantha, P. C. Prat, and A. Ledesma, "Experimental evidence of size effect in soil cracking," Canadian Geotechnical Journal, vol. 49, no. 3, pp. 264-284, 2012.

[33] H. Péron, L. Laloui, T. Hueckel, and L. Hu, "Desiccation cracking of soils," Revue européenne de génie civil, vol. 13, 2009. 